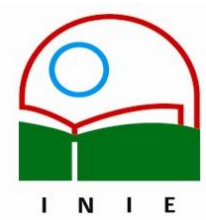

Actualidades Investigativas en Educación

Revista Electrónica publicada por el

Instituto de Investigación en Educación

Universidad de Costa Rica

ISSN 1409-4703

http://revista.inie.ucr.ac.cr

COSTA RICA

\title{
VIGOTSKY Y FREIRE DIALOGAN A TRAVÉS DE LOS PARTICIPANTES DE UNA COMUNIDAD VIRTUAL LATINOAMERICANA DE CONVIVENCIA ESCOLAR
}

THE DIALOGUE OF VIGOTSKY AND FREIRE TROUGH

THE PARTICIPANTS IN A LATINOAMERICAN VIRTUAL COMMUNITY OF SCHOOL 'CONVIVENCIA'

\section{Volumen 9, Número Especial}

pp. $1-30$

Este número se publicó el 15 de noviembre 2009

Célica Esther Cánovas Marmo

La revista está indexada en los directorios:

LATINDEX, REDALYC, IRESIE, CLASE, DIALNET, DOAJ, E-REVIST@S,

La revista está incluida en los sitios:

REDIE, RINACE, OEI, MAESTROTECA, PREAL, HUASCARAN, CLASCO 


\title{
VIGOTSKY Y FREIRE DIALOGAN A TRAVÉS DE LOS PARTICIPANTES DE UNA COMUNIDAD VIRTUAL LATINOAMERICANA DE CONVIVENCIA ESCOLAR \\ THE DIALOGUE OF VIGOTSKY AND FREIRE TROUGH THE PARTICIPANTS IN A LATINOAMERICAN VIRTUAL COMMUNITY OF SCHOOL 'CONVIVENCIA'.
}

\author{
Célica Esther Cánovas Marmo ${ }^{1}$ \\ Colaboran \\ Josefina Noriega Martínez y Victoria Vidergas Birk
}

\begin{abstract}
Resumen: Este artículo tiene la intención de dar a conocer una experiencia virtual construida por participantes de distintas partes de América Latina en el Módulo I -"Pilares y desafíos de la Convivencia Escolar"-, del Diplomado a cargo de la Universidad Iberoamericana León, responsable del nodo de formación de la Red Latinoamericana de Convivencia Escolar. El diseño de dicho módulo se nutre en dos vertientes epistémicas: 1. La perspectiva histórico -cultural de Lev Vigotsky, centrándose en los instrumentos de mediación psicológicos, técnicos y sociales, así como en la criticidad y la conciencia para reelaborar la realidad plateada en situaciones conflictivas experimentadas en el ámbito laboral da cada uno, así cómo se solucionan -o no- las mismas, para lograr el ambiente propicio de una convivencia que permita el proceso de aprendizaje. 2. La visión sociológica y pedagógica de Paulo Freire que, a manera de marco ideológico, alienta lo que se espera acordar para la construcción de estrategias que promuevan cambios promotores de la convivencia. $A$ través de los aportes de los participantes, el texto recupera ideas de los autores mencionados, cuya complementariedad dan fortaleza a la visión de una educación fincada en la crítica y el proceso formativo de la conciencia, donde los seres humanos aprenden a ser sujetos de la historia, -dejando de ser objetos de la misma-, con capacidad para resolver situaciones conflictivas que atentan contra la convivencia cotidiana en cualquier contexto social.
\end{abstract}

Palabras claves: EDUCACIÓN, CONVIVENCIA ESCOLAR, DIÁLOGO CRÍTICO, CONCIENCIA, CAMBIO.

Abstract: This article expounds an on-line experience formed by different Latin American participants during the module "Pillars and Challenges of School Convivencia", which is part of the diploma course Universidad Iberoamericana Leon is responsible for within La Red Latinoamericana de Convivencia Escolar (School Convivencia Latin American Network). The module is nourished from two main epistemic streams. The first, Lev Vigotsky's historic and cultural perspective, which, focusing on psychological, technical and social mediation means, allows for the development of awareness and criticality of the strategies used to re-structure conflicting experiences lived in each one's working environment and of the ways through which these situations have been resolved -or not- so that an adequate environment for convivencia may develop, fostering proper learning processes. The second one, Paulo Freire's socio-pedagogical view, is incorporated as theoretical framework to foster agreements aiming for changes that will promote convivencia. Through participants' contributions, this paper retakes the cited authors' ideas to found a view of education based on criticism and conscience growth, where human beings learn to become subjects of history -breaking away from their role as objects of it-with capacity to solve conflicting situations which threat everyday convivencia in any social context.

Key words: EDUCATION, SCHOOL CONVIVENCIA, CRITICAL DIALOGUE, CONSCIENCE, CHANGE.

\footnotetext{
1 Doctorado Interinstitucional en Ciencias Sociales de las Universidades Autónoma de Aguascalientes y Autónoma Metropolitana, Iztapalapa. Maestría Maestría en Educación de la Universidad Iberoamericana, LeónMéxico. Coordinadora del Doctorado Interinstitucional en Educación. Universidad Iberoamericana León.
}

Dirección electrónica: celica.canovas@leon.uia.mx

Artículo recibido: 28 de mayo, 2009

Aprobado: 9 de noviembre, 2009

2 'Convivencia' is a spanish concept that signifies "living well together" 


\section{Introducción}

En este artículo pretendemos recuperar un contexto virtual, donde dialogan voces latinoamericanas de Perú, Bolivia, Chile, Nicaragua, Costa Rica, Venezuela y México (desde su capital -México DF- y de las provincias de Guanajuato, Guadalajara y Aguascalientes) en torno a la construcción colectiva de conceptos que definieran "los pilares y los desafíos de la convivencia escolar".

Cabe señalar que la planeación del módulo así titulado responde a un diseño holístico, basado en una perspectiva pedagógica que se nutre de dos corrientes epistémicas: la histórico cultural de Lev Vigotsky y la pedagógica-sociológica crítica de Paulo Freire.

La lectura de los registros de las actividades permitió identificar que, a través de los encuentros virtuales de los participantes, fueron emergiendo las voces de: Lev. Vigotsky, psicólogo ruso y de Paulo Freire, pedagogo brasileño. En el deseo de compartir esta experiencia, hemos trabajado en torno a la pregunta: ¿Qué características tiene la mediación, dada a través de los diálogos virtuales, para que se puedan reconocer la conjunción ideológica de Vigotsky y Freire en los conceptos? El análisis de las participaciones nos dio para suponer que tal mediación es semiótica, ya que el sistema de signos culturales, transformados en procesos mentales de los individuos, tienen su origen en la historia que trae consigo la especie humana por lo que, la naturaleza del funcionamiento mental superior, es social.

En este texto se conceptualizan y ejemplifican los temas: proceso de construcción de conceptos; la comunidad virtual como medio colaborativo de aprendizaje, las distintas maneras en que se da la mediación; el diálogo como construcción histórico-cultural del conocimiento y como proceso pedagógico, facilitador en el proceso de aprendizaje, en este caso relacionado con la elaboración de los conceptos claves de la convivencia escolar y el reconocimiento de los desafíos que conllevan el logro de la misma.

\section{Precisiones conceptuales y experiencias virtuales}

Los procesos realizados se organizan a través de los siguientes observables: 1. Definición de términos. 2. El papel de la mediación en las interrelaciones. 3. El diálogo en nuestra comunidad virtual. Cabe señalar que dichos observables son focalizados desde las perspectivas teóricas de Lev Vigostky y de Paulo Freire, autores que parecen dialogar a través de los participantes. 


\section{Un proceso para la definición de términos}

El método para buscar una precisión conceptual se basa en la postura epistémica de Vigotsky, para quien el pensamiento se estructura en unidades constituidas por el significado de cada palabra:

El significado de una palabra representa una amalgama tan densa de lenguaje y de pensamiento que es difícil determinar si se trata de un fenómeno lingüístico o de un fenómeno intelectual. (...). El significado es un fenómeno del pensamiento verbal o del lenguaje significante: una unión de la palabra y del pensamiento. (1962, p. 56)

Este punto de mira teórico nos llevó a diseñar una primera actividad donde los participantes acordaran cómo entendían el término convivir, desde sus diferentes cotidianidades -ya que el trabajo del Módulo I: Pilares y desafíos de la convivencia escolar, se centraría en la identificación de lo que hace posible la convivencia escolar, considerando en ello la posibilidad de asumir y solucionar los momentos de tensión que se plantean, en aras de dicha convivencia-. Con el fin de propiciar la intervención y retroalimentación de todos por todos, se organizaron en equipos de cinco personas y la definición final, obtenida de manera consensuada, se compartió en el foro social, al cual todos los integrantes del grupo general tenían acceso para leer y comentar.

El proceso llevado a cabo fue rico y aleccionador, ya que el diseño de la actividad u objeto virtual proponía la recuperación de las experiencias generadas en los ámbitos laborales de dichos participantes para cumplir el objetivo de identificar y caracterizar los elementos que la sustentan (o sea sus pilares), así como identificar cuáles eran las situaciones de tensión ( 0 , dificultades) experimentadas en el ámbito escolar y cómo se resolvían en función de una adecuada convivencia.

A continuación, -por motivos de espacio-, se toman las acciones de uno de los cinco equipos como ejemplo del proceso seguido. En la elección se tuvo en cuenta que el grupo estuviera integrado por participantes de distintos lugares de América Latina, así como el hecho de que los mismos integrantes establecieron sus propios tiempos para llevar a cabo la tarea y que la asesora del grupo virtual interviniera mediando con preguntas detonadoras de la reflexión. 
Es importante señalar que la estrategia seguida para determinar la extensión de la viñeta es el concepto central de la psicología vigotskyana: la vivencia definida como unidad de análisis que integra las características sociales-interactivas y las individuales-cognitivas.

Para recuperar las intervenciones se identifica de la siguiente manera: el texto editado de la participación precedido por la primera letra de Aportación $(A)$, el nombre del participante, la fecha en que lo hace $(F)$, el lugar de procedencia $(L)$-indicándose el país, el estado y la ciudad; en los casos que se disponga de los tres lugares-, la ocupación $(\mathrm{O})$ y, si el participante interviene más de una vez, sólo conserva la identificación o primeras letras del nombre y la fecha.

\section{Construcción colectiva del concepto "Convivir"}

Aporte (A): "La conceptualización del término "convivencia" demanda de un análisis reflexivo sobre la búsqueda de una interacción pacífica entre los individuos como entes sociales (...). Sin duda, una de las tareas educativas es educar en valores, para la paz, para el mejoramiento comunitario. Ello hace necesario incluir en nuestro vocabulario y en nuestra visión del proceso de enseñanza-aprendizaje el término "convivencia", lo cual, nos llevará a lograr un fin común: La educación en un clima de armonía, que nos conducirá a una meta: la calidad en la educación. Para lograr lo anterior, debemos iniciar con en el entendimiento y la aprehensión del concepto "convivencia" social, para trasladarlo después a la convivencia escolar. (...) entiendo la "convivencia" como la habilidad para interactuar de manera incluyente con los demás, con una actitud de diálogo, en el marco de una normatividad basada en la confianza y en la igualdad. En consecuencia, los elementos que rescato de este término son: actitud, inclusión, diálogo, igualdad, habilidad y normatividad." (Mi.) (F): 9 de septiembre de 2008. (L).: México, Jalisco, Guadalajara. (O): Secretaría de Educación de Jalisco. Centro de Investigaciones Pedagógicas y Sociales. Posgrado.

(A): "En un mundo complejo y multicultural, la educación tiene como prioridad educar para la convivencia pacífica entre los miembros de la sociedad. Lo que implica crear en los estudiantes actitudes de interacción armónica mediante habilidades de diálogo, en el que se dé el reconocimiento del otro en igualdad de derechos y responsabilidades para llegar a acuerdos que permitan la convivencia fraterna. La búsqueda para mejorar la calidad de la educación deberá tener como eje transversal favorecer, en los centros educativos, un ambiente armónico de aprendizaje. Desde lo anterior considero que los elementos de la acción de convivir son: actitud, diálogo, igualdad, derecho, responsabilidad, acuerdos. (Er.) (F): 9 de septiembre de 2008. (L): Quito-Ecuador. (O): Coordinador del Área de Pastoral de la Regional Sierra-Amazonía Fe y Alegría Ecuador.

(A): "Hola Er... es agradable iniciar el diálogo, como verás ya está en marcha el 1er. Módulo. Estuve leyendo tu aporte...interesante desde ya, pero me preguntaba qué es esto que tu escribes como "...reconocimiento del otro", sólo eso. Ayudará mucho tu 
perspectiva desde Ecuador. (Ed.) (F): 11 de septiembre de 2008. (L): Bolivia. (O) Fe y alegría. $(P)$

(A): "Contesto tu pregunta: al hablar de reconocer al otro me refiero a identificar a las personas con quienes convivimos en su especificidad, y desde esa identificación valorarla y respetarla. Es decir, en el momento en que identifico y me identifico con la otra persona, aquel sujeto pasa a ser importante para mí; con el cual quiero compartirconvivir." (Er.) (F): 13 de septiembre de 2008.

(A): "El término de convivencia significa acción de convivir, convivir como "vivir en compañía de otro u otros cohabitar", lo que nos conduce a otro término el de "relación" entre los que conviven, así que la convivencia reclama una relación. Ésta requiere de varios elementos como: el personal, el contextual, el normativo, el comunicativo, entre otros. En este orden, la convivencia es el proceso por medio del cual los seres humanos determinamos la interacción con nuestros semejantes, se requiere de una estructura actitudinal, valoral y normativa, que regule dicha interacción". (Os.) (F): 12 de septiembre de 2008. (L): México, Guadalajara, (O): UPN de Zapopan. (P)

(A): "Con relación nuevamente al concepto "convivir", considero que (...) es importante enfatizar la idea de "Convivencia para la Paz" para ser activos en las dimensiones formativas. Esta idea, tomada de la selección de lecturas realizada por Flavio Rojo, "Algunos temas a desarrollar para la convivencia escolar" (2008, pp. 24-44), es significativa, ya que sin la formación intra-escolar de estas dimensiones será muy difícil educar para una convivencia rica en experiencias e insertada en una regla de oro y que se define en la siguiente frase "El respeto al derecho ajeno es la paz", frase de Don Benito Juárez, (Presidente de México y quien proclamó las leyes de Reforma en este país en el año de 1860). (Ro.) (F): 14 de septiembre de 2008. (L): México, Guanajuato, (O): Secretaría de Educación de Guanajuato.

(A): "Los aportes hechos son muy interesantes. Aquellos que han utilizado el término 'normatividad' sería bueno que lo dimensionaran: ¿Piensan en una normatividad impuesta verticalmente, autoritaria, o es una normatividad acordada de manera reflexiva por los integrantes del espacio social o institucional? Coordinadora. 14 de septiembre de 2008.

(A): "En consonancia con la puntualización de Rosario y respondiendo la pregunta de la C., entiendo que es importante considerar que convivir es un acto dialógico fundamentado en relaciones interpersonales basadas en el respeto y la equidad, contextualizados en un ámbito democrático. (Na.) (F): 18 de septiembre de 2008. (L): Hidalgo, México. (O): Asesora académica de la Universidad Pedagógica Nacional (UPN-Hidalgo). (A)

(A): "Definimos convivir como un proceso social y formativo, por los que los individuos y grupos de personas dialogan para actuar de manera incluyente, en un tiempo y lugar. Es un proceso donde se construye un contexto democrático basado en la interacción de los seres humanos en igualdad de derechos y responsabilidades, que demanda la relación entre diferentes. En síntesis, la convivencia es posible en un marco de normatividades acordadas democráticamente, donde los individuos en colectivos construyan las habilidades, capacidades y actitudes que promuevan el diálogo 
(comunicativo-conductual), la responsabilidad (relación interpersonal), la identificación y el respeto a las diferencias y los objetivos de convivencia para la paz." (Ro. y Ed.) (F): 19 de septiembre de 2008. (Síntesis consensuada realizada por quienes fungieron como Secretaria y Coordinador del equipo).

Esta unidad o vivencia recupera el proceso de construcción del concepto convivir, nos permite imaginar a Vigotsky y a Freire sentados frente a frente conversando desde sus aportes teóricos. El primero nos remite a la idea antes expresada respecto a que la palabra convivir, como todas: "representa una amalgama tan densa de lenguaje y de pensamiento (...)". Para este autor el ser humano se eleva en el funcionamiento mental básico proveniente del capital genético de la especia- a un funcionamiento mental superior, a través de actividades vinculadas a la solución de problemas realizadas socialmente. Él dice: “... todas las funciones psíquicas superiores son relaciones sociales interiorizadas" (Vigotsky, 1981, p. 164) $)^{3}$. Ello se explica a través de una relación en la construcción de los significados: la inter-psicológica y la intra-psicológica. Dualidad que no queda ahí, porque la mediación semiótica, también se apoya en dos contrarios: la organización y la utilización del lenguaje. Ya que por un lado el lenguaje sirve para la reflexión abstracta o descontextualizada desarrollo de conceptos, categorización, razonamientos lógico y científico, donde las palabras se descontextualizan-; por otro lado, la organización del lenguaje se da en la contextualización del mismo. Estas tendencias opuestas actúan simultáneamente sobre la estructura y la interpretación del lenguaje.

El proceso descrito por Vigotsky se percibe en la construcción realizada en cada una de las aportaciones por los miembros del equipo y en el dinamismo de sus acciones vemos cómo se entretejen dicho proceso y ciertos aportes teóricos de Freire sobre la codificación y descodificación de las palabras, así como los temas generadores.

¿Qué quiere decir esto? Para el autor brasileño el proceso de aprender consiste en tres momentos dialécticos e interdisciplinariamente entrelazados que llevan a cabo el maestro (que participa y, a la vez, organiza y reflexiona dicho proceso): a) la investigación temática, donde el alumno y el maestro buscan en el universo del vocabulario del alumno y de la sociedad donde vive, las palabras y temas centrales de su biografía; b) la tematización, donde ellos codifican y descodifican esos temas, buscando una significación social; c) la

3 Citado por Wertsch, J, (2008). "La mediación semiótica de la vida mental: L.S. Vigotsky y M.M. Bajtín”. En Schneuwly, B. y Bronckart, J.P. (Coord.), Vigotsky hoy, p. 115. 
problematización, donde se busca superar una primera visión (que el autor llama mágica) por una visión crítica, donde se origina la transformación del contexto vivido. ${ }^{4}$

Estos señalamientos del pensamiento freiriano dialogan con Viygotsky respecto a los orígenes sociales y la naturaleza del funcionamiento mental, ya que el significado generalizado o categórico de las palabras se vincula con la interacción psico-social; de ahí la necesidad de dominar el significado de la palabra -por lo menos en los sectores más educados de la sociedad-.

El ejemplo de ello lo encontramos en la primera intervención, cuando expresa: “(...) Para lograr lo anterior, debemos iniciar con en el entendimiento y la aprehensión del concepto "convivencia" social, para trasladarlo después a la convivencia escolar. (...) entiendo la "convivencia" como la habilidad para interactuar de manera incluyente con los demás, con una actitud de diálogo, (...)."

Según el psicólogo ruso, el funcionamiento inter-psicológico refleja la existencia de una categorización generalizada, lo que constituye una primera etapa sobre el significado de las palabras fuera de contexto. Posteriormente, según el mismo autor, el ser humano es capaz de reflexionar sobre esas categorías y lo hace más y mejor si pertenece a sectores educados de la población. Estos aportes teóricos del psicólogo ruso no se contradicen con los de Freire, aunque éste no se queda en que tal capacidad se da sólo en los sectores cultos. Recordemos que en su propuesta para alfabetizar adultos, el pedagogo brasileño enfatiza la necesidad de buscar otras formas de propiciar la reflexión de los sujetos de los estratos de población que no habían tenido la oportunidad de ir a la escuela; y es así que propone, como primera etapa del método a seguir, remitir a los participantes a sus biografías, con la idea de que en ellas encuentren los elementos para dominar los significados, lo cual creemos pertinente, ya que su propia historia es el contexto inmediato y aprehensible que tiene cada sujeto. Pensar dicha pertinencia lo corrobora el pensamiento de Alexander Luria, continuador de Vigotsky, cuando expresa que en los sujetos existe:

...la tendencia a apoyarse en las acciones ejecutadas en la vida práctica (y ello) fue el factor de control en las respuestas de analfabetos y sujetos no escolarizados... (ya

4 Lauro de Oliveira Lima, (educador brasileño), fue de los primeros en sistematizar el Método de Paulo Freire. Ver "Método de Paulo Freire: proceso de aceleración de lafabetización de adultos", en Tecnología, educación y democracia, Río de Janeiro, Civilización Brasileña, 1979, pp.175-176. Citado por M. Gadotti “La voz del biógrafo brasileño. La práctica a la altura de un sueño". En Gadotti y Torres (Comp.) (2001), Paulo Freire, una bibliografía. México: FCE, pp. 50 - 126. 
que) los sujetos un poco más educados emplearon la clasificación categórica como método de agrupamiento de objetos... $(1979, \mathrm{p} .71)^{5}$

La segunda etapa freiriana (la tematización) es el comienzo de la reflexión, la que encontramos en Vigotsky como el reconocimiento de la capacidad del ser humano de reflexionar sobre la categorías; es necesario decir que desde la perspectiva histórico-cultural la reflexión juega un papel destacado, ya que el pensamiento es el proceso rector del desarrollo, lo cual se redimensiona al tratarse de los sujetos que nos ocupan: los maestros, ya que para Vigotsky se debe profundizar en el sentido personal, condicionado por la vivencia, en búsqueda de una expresión cultural, así como la histórica de cada persona, en dichos significados. Ejemplo de esto se encuentra en la participación que expresa:

En relación al concepto convivir, considero que (...) es importante enfatizar la idea de "Convivencia para la Paz" para ser activos en las dimensiones formativas. Esta idea, tomada de la selección de lecturas realizada por Flavio Rojo, "Algunos temas a desarrollar para la convivencia escolar" (2008, pp. 24-44), es significativa, ya que sin la formación intra-escolar de estas dimensiones será muy difícil educar para una convivencia rica en experiencias e insertada en una regla de oro y que se define en la siguiente frase: El respeto al derecho ajeno es la paz; frase de Don Benito Juárez, (Presidente de México y quien proclamó las leyes de Reforma en este país en el año de 1860)

Este fragmento discursivo muestra un desarrollo particular del deber ser de la profesión, respondiendo como se espera que proceda una persona adulta: con responsabilidad; su automotivación la hace atender el compromiso de análisis complementado por un nivel de reflexión y criticidad, ello permite que se manifieste con conciencia de lo que hace; en otras palabras, es una profesional de la educación que vincula la práctica con disposición para ejercer su acción docente de manera coherente con sus reflexiones.

La tercera etapa del método freiriano (la problematización), consideramos que podría interpretarse como la capacidad humana de efectuar ciertas operaciones abstractas sobre dichas categorías. Vigotsky, en estudios posteriormente continuados por Luria $(1976,1982)^{6}$,

5 Citado por Wertsch, J. (2008). En Schneuwly, B. y Bronckart, J.P. (Coord.), Vigotsky hoy, p. 118. $6 \quad$ Citado por Wertsch, J. (2008). En Schneuwly, B. y Bronckart, J.P. (Coord.), Vigotsky hoy, p. 117. Volumen 9, Número Especial, Año 2009, ISSN 1409-4703 
estas abstracciones las hacen más y mejor los sujetos educados, como lo mencionamos renglones más arriba, lo cual se evidencia en la definición consensuada por este grupo de profesores sobre el término convivencia:

... es posible en un marco de normatividades acordadas democráticamente, donde los individuos en colectivos construyan las habilidades, capacidades y actitudes que promuevan el diálogo (comunicativo-conductual), la responsabilidad (relación interpersonal), la identificación y el respeto a las diferencias y los objetivos de convivencia para la paz.

Tal definición del término convivencia denota la formación académica de los participantes, ejemplificando el pensamiento vigotskyano sobre el papel cultural de esta profesión; ellos son sujetos portadores de una cultura de este tiempo y de este lugar.

Ello nos hace voltear nuestras miradas a Freire, quien lleva a cabo su método educativo con adultos analfabetos, para ello busca en las ciencias sociales los elementos que permitan comprender la realidad y poder intervenir para transformarla; de ahí que defina a la educación como un acto político, como acto de conocimiento y como acto creador. En la definición consensuada del término convivencia las palabras tienen ecos lejanos de la postura freiriana, esto se explica por las diferencias, porque el proceso formativo de los maestros proviene de contextos histórico-culturales diferentes. Sin embargo, la vivencia recuperada en el diálogo virtual hace que ambos autores pongan en claro que el aprendizaje se basa en las interrelaciones complejas de los binomios educandos-educadores, donde juegan un rol preponderante las palabras y las experiencias compartidas.

\section{La mediación: sinónimo de interrelaciones}

Desde la perspectiva de Vigotsky la mediación indica una relación con alguien que es atravesada por la relación de otro. Entonces, corresponde explicar qué papel juega la mediación entre los sujetos actores y también en las interrelaciones que ocurren en la mente de cada uno de ellos. El conjunto de procesos mentales superiores son considerados por Vigotsky como funciones de actividades mediadas, dichas actividades de mediación la cumplen: 1) los instrumentos psicológicos, 2) los instrumentos técnicos y 3) los agentes sociales. Además, para Vigotsky la mediación es parte de una trilogía de elementos, junto a 
los procesos mentales superiores y a la acción del pensamiento. ${ }^{7}$ Esto lo explica la propuesta epistémica de Lev Vigotsky, quien a los signos -identificados como instrumentos psicológicos- los describe como recursos para dominar los procesos mentales. Dichos instrumentos psicológicos son: la lengua, los sistemas para contar, los esquemas de símbolos algebraicos, las obras de arte, las técnicas nemotécnicas, la escritura, los esquemas, diagramas, mapas, dibujos técnicos y todo tipo de signos convencionales. (Vigotsky, 1961/80, pp. 136 y 137) ${ }^{8}$. Él sostiene que los seres humanos se dominan ellos mismos mediante los símbolos culturales externos, del sujeto actor depende -por lo tanto -, no ser subyugados por tales símbolos:

Puesto que el estímulo auxiliar posee la función específica de la acción inversa, transfiere la actividad psicológica a formas superiores y cualitativamente nuevas y permite mediante la ayuda de estímulos extrínsecos, controlen su conducta desde el exterior del desarrollo de las funciones psíquicas superiores. (Vigotsky, 1978, p. 40) ${ }^{9}$

Ese énfasis puesto por el psicólogo ruso en la posibilidad de autoconstrucción hace que el sujeto sea activo en el logro de su desarrollo, lo cual es muy importante para alcanzar los objetivos particulares del proceso de aprendizaje. Para que éste sea dinámico el autor mencionado enfatiza la automotivación interior, donde cumple un papel importante la mediación social, como facilitadora de acciones adecuadas, y a la vez retadoras, así como el trabajo cooperativo. En el caso que analizamos hay momentos que ejemplifican tal mediación, como se ilustra en la viñeta seleccionada:

(A): "COMPAÑERAS, nos hacen falta sus participaciones, cómo van, confío que este sábado ingresemos a la página y al foro. El trabajito del cuestionario que nos puso Josefina estuvo muy bueno, creo que tenemos muchos elementos en el foro: la comunicación, el conflicto, manuales de convivencia, el caso de la escuela de Bogotá esta genial. (Te.) (F): 4 de octubre. (L): Ecuador. (O): Pastoral en "Fe y Alegría" Movimiento de educación popular.

(A): (...) la verdad creo que sirvió de mucho este foro y he aprendido mucho en lo particular de ustedes $\operatorname{dos}(. .$.$) aunque confieso que es la primera vez que tomo un diplomado en esta$

7 Más tarde Bülher agregaría un elemento importante que denominó la internalización dado que lo que aparece primero como un mediador sígnico externo o una comunicación interpersonal, más adelante se convierte en un proceso psicológico interno. Así como sus continuadores aportaron la teorización de procesos "primitivos", ubicados entre los procesos mentales superiores y las funciones naturales. (Kozulin, 1990, pp. 116 - 118 - 119)

${ }_{8} \quad$ Citado por H. Daniels, (2003), Vygotsky y la pedagogía, Barecelona: Paidós, p.33.

9 Citado por H. Daniels, (2003), Vygotsky y la pedagogía, Barecelona: Paidós, p.33. 
modalidad, pero me gusta, me gusta (...).(He) (F): 13 de septiembre. (L): Guanajuato. (O): Maestro de $3^{\circ}$ de primaria.

La viñeta transcrita permite reconocer factores que hacen posible la mediación social, como: el liderazgo de uno de los iguales -integrantes del equipo- logrado a través de la participación comprometida con la actividad diseñada; el entusiasmo compartido ante la tarea a realizar, lo cual nos habla de la automotivación para el aprendizaje y, a la vez, del sentido real del quehacer cooperativo -donde se estimula a los otros en las acciones por realizar-, lo cual desencadena el diálogo, donde la respuesta demuestra la mediación social -interpsicológica- de quienes aportan conocimientos, ayudando a la comprensión de lo que transmite el otro ${ }^{10}$, así como la respuesta positiva a la mediación del instrumento técnico que es la virtualidad. Este último tipo de instrumento, desde la perspectiva vigotskyana, debe enfatizar el interés del proceso para llegar a una respuesta de calidad, atendiendo la historia del sujeto que lo utiliza.

Vigotsky remarca que los elementos contextuales juegan un rol muy importante, ya que los instrumentos disponibles se encuentran en un lugar y en un tiempo determinado; ambos factores son especialmente importantes en el caso que nos ocupa, ya que respecto al tiempo, el hecho de integrarse a una comunidad de aprendizaje personas de diferentes latitudes acentúa la diacronía de los procesos personales que, de por sí, favorece el entorno virtual; dicha diacronía puede ser conflictiva, si no existe una actitud de comprensión hacia tal situación. Tal fue el caso que recuperamos a continuación:

(A): "Es que no he tenido respuestas de nadie en el correr de la semana. Luego, todo lo encuentro el lunes, en lugar del domingo, como lo indica el cierre de la actividad." (Ra.) (F): 16 de octubre. (L): Bolivia, La Paz. (O): Académica.

(A): "Compañera nosotros sí respondemos en domingo ¿No estará influyendo la hora de tu país? Para tener presente los husos horarios, sería bueno incorporar en la plataforma, la hora de los países que están representados por quienes participamos, así no habría lugar para reclamos de este tipo. ¿No? (Ga.) (F): 17 de octubre. (L). México, Aguascalientes. (O): Maestra.

10 Para Vigotsky la ayuda mutua -o apoyo mutuo- es de suma importancia, ello equivale a la cooperación, donde la ayuda significa la intención de traspasar lo factible para hacer que lo aparentemente imposible, sea realidad. Ello se logra con el apoyo de otra persona, la que coopera en el desarrollo del sujeto que aprende. 
NOTA. Así se hizo, las personas de apoyo tecnológico incorporaron imágenes de relojes con los horarios de los distintos países.

En cuanto al medio electrónico en que se desenvuelven las acciones de los procesos nos remite a la idea de otros instrumentos, definidos por Vigotsky como instrumentos técnicos. De ellos dice que son los que provocan cambios en los objetos mismos. En el objeto de estudio que se construye en el caso que nos ocupa, los instrumentos técnicos son la computadora y el entorno virtual, ya que, al tener en cuenta que para Vigotsky los instrumentos técnicos son órganos artificiales cuya "utilización (...) modifica la actividad natural de los órganos y amplía, hasta el infinito, el sistema de activación de la funciones psíquicas..." (1987, p. 102) ${ }^{11}$. Por lo tanto, pienso que el uso de la computadora y del entorno virtual, no sólo posibilitan las interrelaciones sino que, además, brindan las posibilidades de dinamizar el proceso de escritura que se quiere provocar y observar. En consecuencia, su uso estaría promoviendo la activación del conjunto de procesos mentales superiores de los sujetos actores que participan. En nuestro caso de estudio el instrumento técnico es la computadora u ordenador y el contexto virtual que se crea con el uso de la máquina.

\subsection{Asunción de la mediación a través de una comunidad virtual}

Antes de entrar en el tema indicado por el subtítulo, creemos pertinente seguir la postura vigotskyana de definir qué entendemos por comunidad virtual, ya que ello permite precisar desde qué perspectiva se asumirá el proceso de mediación a través de la particularidades que tiene el instrumento a emplear.

Estimamos conveniente comenzar la búsqueda en dónde y cuándo se origina la palabra comunidad. Etimológicamente comunidad proviene del término comoine (latín antiguo) que significaba "conjuntamente" o "en común"; el sustantivo commune significaba comunidad. También, hay que considerar el término "commonis" del latín antiguo, que provino de "communis", cuyo significado era "corresponsable", "cooperante", así como: "que colabora en realizar una tarea". (Se observa que la palabra "communis" está compuesta por los términos "com" + "munis"; de los cuales, "munis" proviene del término latín "mune" y

11 Citado por Gloria Fariñas el jueves de de noviembre de 2006. En este texto se transcribe sólo la cita hecha por la Dra. Fariñas; ella es un fragmento de la respuesta a la pregunta formulada en el foro virtual con integrantes del Seminario de Autoformación de la UIA León: "Podrías ampliar un poco el sentido que, desde el enfoque histórico cultural tienen los términos artefactos, herramientas e instrumentos. ¿Son sinónimos o son diferentes? (...)" 
significaba: "servicial" o "cumplidor de su deber") ${ }^{12}$. Para efectos de este texto, es interesante destacar que en el siglo XV se utiliza el término "comunicar", tomado del latín communicare como sinónimo de "compartir" o "tener comunicación con alguien"13.

Esta precisión sobre cómo se entiende el término comunidad es importante dado que se lleva a cabo de manera virtual. Especialmente cuando el significado de esta palabra virtual alude a la "intención de realizar un trabajo, aunque no se realice"; (este significado proviene del término latín "virtus"). De ahí la necesidad de poner énfasis en el ejercicio del compromiso asumido en una comunidad integrada por voluntad propia para lograr un objetivo específico a través de la acción social de los individuos del grupo para dar y recibir ideas que permitan construir el aprendizaje. Si no se asume la comunidad así, la virtualidad del proceso pone en riesgo que el proceso no se lleve a cabo.

Veamos un ejemplo de cómo se asume la plataforma para poder entender qué alcance tiene el instrumento técnico en el caso observado:

(A): "Nuestras asesoras crearon el espacio de una verdadera convivencia para generar aprendizaje. La lectura y fundamentación, refuerza nuestro pensar, enriquece con nuevas herramientas y nos abre horizontes." (Te) (F): 23 de octubre de 2008. (L): Ecuador. (O): Pastoral en "Fe y Alegría" Movimiento de educación popular.

(A): "Aquí convivimos virtualmente y hemos sido testigos, quienes por primera vez tenemos una experiencia en línea, de la forma en que se construye una comunidad de aprendizaje postmoderna." (Co.) (F): 26 de octubre de 2008. (L): Guanajuato. (O): Maestra de primaria en comunidad rural.

(A): "En otro sentido, el intercambio de experiencia y la oportunidad de compartir puntos de vista con todas (os) en este maravilloso espacio de aprendizaje. En lo personal ha sido de una gran riqueza las diferentes etapas y momentos de trabajo impactando de tal forma que ha extendido mi horizonte en torno a la convivencia escolar, sus alcances y hasta la forma de poderlo trabajar." (Li.) (F): 22 de octubre de 2008. (L): Guanajuato. (O): Supervisora de preescolar.

(A): "Es muy enriquecedora la experiencia de leernos, nos permite acercarnos aún cuando la distancia entre nosotros es considerable. Yo he aprendido de todos (as)." (El.). (F): 25 de octubre de 2008.

(A): "Comparto la idea de los aprendizajes, los documentos y la experiencia de hablar con muchos de ustedes a través de la plataforma, ha enriquecido al grupo y cada uno de

\footnotetext{
${ }^{12}$ Corominas, J. (1987). Breve diccionario etimológico de la lengua española. Madrid: Gredos, p. 163.

${ }_{13}$ Corominas, J. (1987). Breve diccionario etimológico de la lengua española. Madrid: Gredos, p. 163.
} 
nosotros. En especial nos pone a pensar como trabajadores de la cultura en el entramado social." (An.) (F): 23 de octubre de 2008. (L): Colombia. (O): Maestra.

En lo que antecede se puede identificar cómo perciben los participantes a las prácticas de mediación en una comunidad virtual: 1) Es una situación psicoafectiva ${ }^{14}$, generadora de aprendizaje (creación del espacio virtual promotor de la convivencia adecuada para aprender). 2) Denota la presencia y la práctica de instrumentos de mediación (las lecturas, la reflexión fundamentada de las mismas para desarrollar el pensamiento. Las herramientas adecuadas para construir el conocimiento). 3) Enfatiza a la plataforma como un medio que propicia el trabajo colaborativo (dos agentes de mediación: el instrumento técnico y el factor social). 4) El diálogo como agente promotor en intercambio de experiencia (crea un espacio donde hay oportunidad de compartir, para aprender; y hace de los sujetos, seres sociales, seres históricos y culturales).

El diálogo virtual analizado permite identificar qué tan compleja es una unidad donde, por un lado, se representa el contexto y, por otro lado, cómo experimenta cada participante la situación, es decir, que todas las características ambientales y todas las personales están representadas en una experiencia emocional; según Vigotsky (1994, p. 8) “... en una vivencia siempre estamos frente a una unidad indivisible de las características personales $y$ de las características situacionales". Lo que queda expresado de manera explícita en lo que señalan (F.), (El.) y (An., quienes dicien, respectivamente: "La lectura... refuerza nuestro pensar"; “... experiencia de leernos”; “... la experiencia de hablar con muchos de ustedes...". ${ }^{15}$

En síntesis, el análisis del proceso dado en el diálogo de los participantes permite entender a la comunidad virtual, es como un espacio social donde los sujetos actúan de manera corresponsable y de forma cooperativa, asumiendo por voluntad, y de manera consciente y consistente, en atención al proceso diseñado, cuyos objetivos de aprendizaje

\footnotetext{
14 Desde la perspectiva histórico-cultural, Vigotsky llamaría a esa "situación psicosocial" una situación psicológica (G. Fariñas, 2009).

15 Desde la perspectiva histórico-cultural, según Fariñas (2007, p. 61) "Las unidades de análisis, al derivarse en alguna forma de la situación social del desarrollo, no pueden desconsiderar las tesis fundamentales que concurren en este constructo: $1 \mathrm{La}$ convergencia dinámica interpersonal y lo intrapersonal construida por el sujeto. La unidad de lo cognitivo y lo afectivo (vivencia) 2. La referencia a la personalidad. 3 El movimiento evolutivo, genético de los fenómenos, no el estudio de las dinámicas subjetivas cosificadas o automatizadas (fosilizadas al decir de Vigotsky)."
} 
pautan las actividades donde se incluyen elementos de mediación, tales como los instrumentos psicológicos, los técnicos y la mediación social.

Esta estructuración compleja de elementos y acciones implica que la comunidad virtual se concibe como un contexto dinámico. Por lo cual pasaremos a definir cómo concebimos al mismo.

\section{La comunidad virtual como contexto cultural contemporáneo}

Antes acordaremos qué se entiende como contexto:

(...) un mundo social constituido en relación con personas actuando, contexto y actividad aparecen inescapablemente flexibles y cambiantes. La conclusión es que el aprendizaje es ubicuo en la actividad en curso, la actividad situada siempre implica cambios en el conocimiento y en la acción, centrales en lo que significa el aprendizaje: la participación en la vida diaria puede ser considerada como un proceso de cambio de la comprensión en la práctica o, lo que es lo mismo, (a través del) aprendizaje. (Lave, 1996, p. 133)

Esta definición conlleva en su primer enunciado la clave de la existencia del contexto, ya que se trata de "un mundo social constituido en relación con las personas actuando", tal actuación se asegura en la asunción de formar parte de comunidad, como una actitud de corresponsabilidad, acordada para la realización de la actividad de escribir. Sin embargo, no se puede dejar de considerar lo que agrega el autor mencionado: “... contexto y actividad aparecen inescapablemente flexibles y cambiantes", lo que hace pensar en la necesidad de construir esa conciencia de corresponsabilidad a través de los dos factores que menciona el mismo Leve: por tratarse de "una actividad situada" y que los participantes asumen desde el entendido de que se trata "de un proceso de aprendizaje diferente", donde tienen que ver el instrumento o herramienta (en este caso representado por el medio electrónico) en que se opera, deberán asumir el medio virtual como un proceso diferente, en el que la novedad juega un rol decisivo para ese involucramiento corresponsable y cooperativo.

Otros elementos a tener en cuenta en la estructura del contexto son las actividades diseñadas u objetos de aprendizaje. Todos cuentan con: objetivos, lo que se piensa lograr en cada uno de los objetos de aprendizaje diseñado; contenidos, temas a tratar; explicación-aplicación, cómo se abordan dichos contenidos y cuáles son las actividades y 
tareas a realizar; duración de la actividad u objeto de aprendizaje y la autoevaluación, donde cada estudiante podrá constatar lo significativo del proceso que le haya redundado en un aprendizaje del conocimiento que se plantea construir.

Dichos elementos tienen que guardar coherencia, tanto interna en cada objeto de aprendizaje, como externa en cuanto a la relación que tienen entre sí. Además, por ser dirigido a un público diverso, en cuanto a procedencia y formación, así como por su índole virtual, deben de ser claros y precisos. Para lo cual, consideramos de extrema importancia tener una perspectiva pedagógica ${ }^{16}$, definida antes de comenzar el diseño curricular; de lo contrario, se corre el riesgo de estar diseñando un proceso mecánico.

¿Cómo vivenciaron ese diseño virtual los participantes?

Ya hemos recuperado algunas vivencias que responden esta pregunta; sin embargo, asumir un aprendizaje de esta índole no es fácil. Ello se manifiesta en la siguiente viñeta:

(A): "Hola compañeros. Iniciamos otra semana de nuestro diplomado y quiero agradecerles todo el apoyo, porque la verdad me estreso mucho, porque no domino mucho esto de la plataforma y me confundo mucho también con las instrucciones. Muchas gracias por su apoyo (...). Para esta semana ya no quiero ser coordinadora, con mucho gusto participo y si alguien necesita de mi apoyo, trataré de dárselos. (Ma.B.) (F): 22 de septiembre de 2008. (L): México, Puebla, Puebla.

(A): "Me preocupa un poco que sea jueves y no se haya llevado a cabo la actividad, el fin de semana yo tengo dificultad para estar conectada, puesto que viajo a cuatro ciudades diferentes por compromisos personales. Me será muy difícil atender el curso sábado y domingo, a mí me gustaría que pudiéramos adelantar un poco a este trabajo y me propongo como secretaria para ir realizando una redacción general de las aportaciones que hasta el momento hemos hecho tres de nosotros. Si están de acuerdo por favor contesten." (Mar.) $(F)$ : 24 de septiembre de 2008. (L): México, Guanajuato, Acámbaro. (O): Psicóloga educativa.

(A): "Con mucho gusto puedo ser la Coordinadora... Mi problema es que los fines de semana se me es difícil el acceso a INTERNET." (May.) (F): 26 de septiembre de 2008. (L): Venezuela. (O). Maestra de enseñanza básica.

16 Para Best la discusión sobre qué significa el término pedagogía, se remonta al siglo XIX cuando Henri Marion dice que: "La pedagogía es (...) la ciencia y el arte de la educación. (...). Yo la definiría como la ciencia de la educación. ¿Por qué ciencia, en lugar de arte? Porque (...) la sustancia de la pedagogía reside mucho menos en los procesos que pone en juego que en el razonamiento teórico por medio del cual descubre, evalúa y coordina estos procesos." Citado por Harry Daniels, (2003), pp. 18-19. 
Las dificultades que expresan los participantes son, principalmente, la falta de conocimiento del manejo del instrumento y la diacronía en la realización de las actividades; no obstante, hay disposición para solucionar ambos problemas.

En síntesis, la comunidad virtual como contexto se estructura con los siguientes elementos: sujetos actores (éstos son: la diseñadora de los objetos de aprendizaje - en este caso, quien ahora escribe y también funge de asesora, los participantes en el proceso de aprendizaje); el diseño de la mediación (a través de los instrumentos psicológicos comprendidos en el diseño de los objetos de aprendizaje-, y de los instrumentos técnicos -la computadora u ordenador que conlleva el uso de la plataforma que provoca al virtualidad-, así como la mediación social a través de las acciones cooperativas para el aprendizaje). Dichos elementos se articulan de múltiples maneras y de forma dinámica dando lugar a los procesos mentales superiores. Estos procesos son explicados por Vigotsky como funciones psicológicas específicas, que no pueden identificarse ni ser definidos de manera precisa ${ }^{17}$.

En cuanto a la acción del pensamiento, Vigotsky considera que las ideas se construyen a partir de las experiencias del sujeto actor, generadas por las acciones de él mismo en su entorno social, donde -como se dijo antes- juega un importante papel la memoria histórica del sujeto actor. Por consiguiente, la automotivación en este tipo de sujeto actor es el elemento prioritario en su desarrollo cognitivo, ya que el pensamiento se da mediante el desarrollo del ser humano. La situación social del desarrollo es una situación psicológica creada por el sujeto en desarrollo, gracias a su interrelación con los otros, luego está dentro-afuera; mientras que las intrapersonales son internas de los mismos, lo cual permite decir que al pensamiento lo entendemos como una interiorización mental del discurso social, que cada sujeto actor hace suyo, al procesar dicho discurso con lo que le resulta significativo. ${ }^{18}$

17 Tradicionalmente la psicología los ha denominado: atención voluntaria, memoria lógica, formación de conceptos, etc.; esto en cuanto a los niños (Kozulin. 1990: 114). En el nivel superior de enseñanza, según Gloria Fariñas (2005, p.17), para "el enfoque histórico cultural, la adquisición del conocimiento es una vía para el enraizamiento del sujeto en la cultura. El conocimiento adquirido condiciona de forma compleja la adquisición de formaciones psicológicas superiores (pensamiento teórico, motivación profesional, conciencia idiomática, etc.)." Para esta autora, Vigotsky dice que dichas formaciones se estructuran con una acumulación de experiencia generada por y en la memoria histórica.

18 La ley genética del desarrollo cultural expresa que “...Cualquier función en el desarrollo cultural del niño aparece en escena dos veces, en dos planos; primero, como algo social, después como algo psicológico; primero entre la gente, como una categoría interpsíquica, después, dentro del niño, como una categoría intrapsíquica". Citado por Fariñas (2005), p.161. 
En el ideario de Freire encontramos una dimensión de la categoría acción del pensamiento, con cierto grado de similitud a las ideas del psicólogo ruso; Freire afirma: “(...) Nadie se educa solo. Los hombres se educan juntos, en la trasformación del mundo." Cita de Freire utilizada para corroborar la idea de que "la educación se vuelve un proceso de formación mutua y permanente" (Gadotti, 2001, p. 61). En ello hay una valoración del saber de todos donde ese saber se pone al servicio del cambio social. Ambos pensadores se asocian en el hecho de que para ellos la conquista de la palabra es la conquista de la historia, o como lo expresa Fariñas remitiéndose a C. Marx -en su 'Tesis sobre Feuerbach'-, quien afirma que al proponer, el sujeto logra transformar al mundo y se transforma a sí mismo.

Por lo antes expuesto se puede decir que la mediación es una actividad social que genera procesos mentales superiores. Al respecto dice Vigotsky: “... el hombre crea, él mismo, estímulos que determinan su reacción y los utiliza en calidad de medios para dominar los procesos de la propia conducta...". (1987, p. 84) Y más adelante lo complementa diciendo que: "el proceder del hombre está determinado, no por estímulos presentes, sino por una situación psicológica nueva o distinta, creada por el mismo hombre..." (1987, p. $89)^{19}$.

Por lo tanto, entiendo que la mediación es una actividad compleja donde está presente el quehacer social del sujeto en el grupo y, a la vez, la historia cultural del propio sujeto, manifestado en su acción particular como sujeto actor en desarrollo.

\section{El diálogo como instrumento del sujeto o agente mediador}

Desde la perspectiva histórico-cultural, la comunicación es la acción de un individuo dirigida a otro, ambos enmarcados por las relaciones sociales de un grupo dado. Para Vigotsky el desarrollo no se da como un proceso autónomo interior del sujeto respecto al ambiente, sino que la relación sujeto-ambiente se da a través de un proceso mediado por el grupo social al que pertenece el sujeto. Ello significa que la comunicación adecuada es el diálogo, ya que da la posibilidad de que cada individuo actúe sobre otro y, a la vez, que el otro actúe sobre él, constituyendo el modelo y el origen de la transformación de su propia

19 Esta cita y la que la antecede es realizada por la Dra. G. Fariñas, (2007), en el Seminario impartido en la UIA León, "La perspectiva histórico culturalista sobre el desarrollo de valores". 
actividad. En otras palabras, el desarrollo va del plano inter-psíquico hacia lo intra-psíquico; o sea que "la naturaleza del propio desarrollo cambia, pasando de la biológica a la sociohistórica" dice Vigotsky (1962).

Aceptar que "los signos y las palabras sirven primero y ante todo como instrumentos para el contacto social con el otro" $(1978 a, 29)$ es ubicar al diálogo como una característica primordialmente humana, la capacidad de explicar las formas extremadamente complejas de la conciencia del ser humano y ello no es posible concebirlo si sólo se explica como organismo humano, tal como lo dice Luria:

Los orígenes de la actividad consciente y del comportamiento "categórico" no debieran buscarse en la sinuosidad del cerebro humano o en las profundidades del alma humana, sino en las condiciones exteriores de vida. Por todo ello... se han de buscar sus orígenes en los procesos externos de la vida social, en las formas sociales e históricas de la existencia humana. (1982, p. 25)

Por consiguiente los espacios intersubjetivos de diálogo a un mismo nivel son tan importantes como la misma actividad. Como explica G. Fariñas (2001 a): "No se trata del desarrollo de meros ejecutores ni de meros oradores, estamos hablando del desarrollo responsable que no debiera ser otro que el integral' (2007, p. 112). La misma autora basada en V.V. Davidov y V.I. Slobodchikov, (1991)- afirma que "el aprendizaje creativo y responsable, exige un diseño educativo y una realización, nada tradicionales."

Precisamente en la concepción de cómo dialogar en el ámbito educativo es que coinciden Vigotsky y Freire. Ya que para Freire el diálogo es una relación horizontal basada en el respeto a quienes se educan; a quienes hay que escuchar y tolerar, ya que la tolerancia es "la virtud de convivir con diferentes para poder luchar contra antagónicos". ${ }^{20}$

En el contexto virtual del Módulo I son muchos los procesos de diálogo que se dieron, de los cuales ya hemos visto algunos. A continuación, recuperamos una vivencia donde los participantes comparten cómo entienden el quehacer educativo, el objetivo es demostrar qué de Vigotsky y o de Freire se percibe en el diálogo virtual:

(A): "Realmente el tema de la educación es cosa seria, ya no estamos en el tiempo de impartir conocimientos como si nuestros chicos fueran recipientes, menos mal,...ahora

20 M. Gadotti, (2001), cita a Freire, p. 65

Volumen 9, Número Especial, Año 2009, ISSN 1409-4703 
contemplar la educación como tema de convivencia escolar desde el cambio, la dignidad y la esperanza supone ya un esquema de tres palabras para un macro-trabajo de comunidad escolar." (Te.) (F): 15 de octubre de 2008. (L): Ecuador. (O): Pastoral en "Fe y Alegría", Movimiento de educación popular.

(A): "Totalmente de acuerdo, debemos educar para la vida y no sólo educar para la escuela. Ir más allá de los límites..." (Co.) (F): 15 de octubre de 2008. (L): Guanajuato. (O): Maestra, primaria en zona rural.

(A): “... creo este mundo materialista nos ha envuelto y hemos descuidado lo más valioso que tenemos como educadores que es lo humano partiendo de atender al otro como ese ser que necesita de nuestra ayuda y verlo como tal con defectos, virtudes y desaciertos que algunos se preocupan más por cubrir la currícula que por lo que le sucede al alumno(...) A los maestros acá que tienen doble turno no tienen la oportunidad de conocer a sus alumnos, (...) la dignidad del docente, acá ha sido muy golpeada el docente por la sociedad, ya no tiene el maestro el status de antes". (GI.) (F): 16 de octubre de 2008. (L): Guadalajara. (O): Psicóloga educativa.

(A): “... la situación golpeada de las y los docentes es verdad los sueldos son bajos y la situación familiar no es para nada sencilla (...) ser docente es un desafío, y eso hay que recuperar: se es docente porque somos gestos, porque decimos con nuestra vida que es posible... no somos docentes porque enseñamos a leer literalmente o escribir... sino porque enseñamos a leer y escribir en nuestra vida y con nuestra vida, y así, más que el que yo enseñe, es que todos aprendemos y compartimos saberes". (Te.) (F): 16 de octubre de 2008.

(A): “... me interesan mucho tus aportes y también los de los demás compañeros, debemos ir pensando, si es que el sistema latinoamericano de educación, quiere hacernos sentir, desmotivados o tener una propuesta mediocre como países del tercer mundo. Mantenernos en este estatus de país en vía de desarrollo". (An.) (F): 19 de octubre de 2008. (L): Colombia. (O): Maestra de Primaria.

(A): "Con respecto de lo que dice An., precisamente el sábado acabo de escuchar la presentación de una tesis doctoral sobre este tema y según el autor hay como una intención por así mantenernos desmotivados y mediocres. Entonces cabe pensar que el Estado juega con un doble discurso. Habrá que aprender a actuar y salir adelante desde el trabajo en el aula". (Li.) (F): 19 de octubre. (L): Guanajuato. (O): Supervisora de preescolar.

En la recuperación de la unidad o vivencia del diálogo de los participantes vuelve a crear el escenario propicio donde interactúan nuestros dos autores. Desde la perspectiva vigotskyana las relaciones humanas se dan a través de un intercambio dinámico de ideas con los demás y también consigo mismo, lo cual redunda en el desarrollo propio; siguiendo esta línea de pensamiento podemos decir que en el análisis y la comprensión de lo que puede implicar la comunicación virtual, resulta significativo lo que dice Vigotsky (1987, p. 162): “...El hombre a solas consigo mismo, sigue funcionando en comunión (con los otros)...", en el entendido de que tal comunión se ve facilitada por el instrumento técnico, lo 
cual torna esa soledad consigo mismo en una necesidad de intervenir con responsabilidad. Este es uno de los valores que pautan el ser del sujeto en el desempeño social del quehacer virtual, ya que tenemos en cuenta que son los valores lo que "... en el papel de orientadores de la personalidad, (su práctica) es indicativa del desarrollo de una personalidad integrada y de un comportamiento intrínsecamente consistente" (Fariñas, 2001, p.113).

Acorde con este planteamiento interpretativo de la comunicación horizontal en un proceso activo de aprendizaje, también aflora el pensamiento freiriano como cuando el primer participante promueve la necesidad de cambiar la educación (estilo bancario) y educar para la vida. Los participantes asumen sucesivamente que sólo se enseña bien se hay alegría y esperanza, así como la noción consciente del que enseña sobre su necesidad de seguir aprendiendo, como ser humano inacabado. Además, Freire sostiene que: "Es preciso insistir: este saber necesario al profesor -que enseñar no es transmitir conocimientono sólo requiere ser aprendido por él y por los educandos en sus razones de ser -ontológica, política, ética, epistemológica, pedagógica- sino también requiere ser constantemente testimoniado, vivido". En la construcción del diálogo transcrito vemos cómo se recupera la acción dialéctica entre la práctica y la teoría; de la capacidad de soñar y, a la vez, enseñar a aprehender la realidad con la convicción de un cambio posible.

En síntesis, las palabras de los participantes nos remiten a pensar en las ideas que definen lo que es la educación. Para Vigotsky: “... El mismo proceso de educación siempre se realiza en forma de cooperación... y representa un caso específico de interacción de formas e ideales... (...) “... toda educación constituye una fuente de desarrollo, (...) (la educación es buena) cuando adelanta el desarrollo..." (T.2, p. 14). En lo cual Freire corrobora desde la concepción de una relación pedagógica, donde el diálogo establecido educa tanto al educando como al educador, al integrase ambos en un proceso de formación mutua y permanente. Entonces, el horizonte se amplía, ya que la educación no sólo desarrolla a los sujetos, sino que promueve la liberación con la transformación radical de la realidad, a través del fomento de una lectura crítica del mundo.

\section{Dialogando sobre experiencias conflictivas}

La perspectiva pedagógica que pauta nuestro quehacer en el espacio virtual del Módulo I la hemos asumido en su dimensión social, es por ello que nos interesa observar el desarrollo de los sujetos actuando en el contexto de la comunidad virtual. En ese escenario, 
a través de los ejemplos ya expuestos, hemos comprobado la eficacia de la mediación social materializada en los diálogos. Como últimos ejemplos de este artículo veremos cómo el proceso grupal abrió espacios para que los participantes plantearan ciertos conflictos, tomados de la cotidianidad laboral y construir las estrategias que permitían solucionarlos.

Entendemos que el conflicto es inherente a la interacción humana. Existen conflictos entre los seres humanos, así como los hay en y entre las áreas y ámbitos en los que se desarrolla la vida cotidiana de los individuos, los grupos, las instituciones, las comunidades. La resolución de los mismos se refiere tanto a la superación de los obstáculos que se presentan como a los procesos que implican los caminos que conducen a la satisfacción de las necesidades: los acuerdos y desacuerdos, los encuentros y desencuentros, las tareas complementarias, las diferencias y los juegos de poder, las coincidencias y los objetivos en común.

Desde la perspectiva de la psicología social el conflicto es un motor necesario, ya que al presentarse pone en funcionamiento la contraparte para buscar la solución más viable. En tal proceso la acción mediadora es necesaria e insoslayable en el logro de la armonía de los elementos, mismos que, al confrontarse, producen la situación conflictiva.

La situación conflictiva en el ámbito educativo por consiguiente, puede -y debe- ser una manera de darnos cuenta de la realidad que provoca tal situación; ese darnos cuenta es un proceso de elaboración de esa realidad (que puede ser externa a nosotros, y de nosotros mismos percibiendo esa realidad). ${ }^{21}$ Para el enfoque histórico-cultural la conciencia es emergente, pero depende de ciertas condicionantes históricas y culturales, que son operadas por el sujeto en desarrollo en una situación social, también, en desarrollo. Desde esta perspectiva, la conciencia es un proceso crítico de la realidad, en la que somos parte; paralelamente, la conciencia es una cualidad de ese mismo proceso (Como son procesuales, se transforman en resultados, ya que en la dialéctica unos procesos se pueden convertir en otros) $)^{22}$.

21 Según Leontiev -siguiendo a Vigotsky, profundiza el término conciencia- la que define como el reflejo doblado de la realidad, es decir, el saber que sé, el saber que estoy viendo, analizando y sintiendo la realidad. Por consiguiente, la conciencia es cualidad en los procesos y, a la vez, es proceso ya que es inherente a los mismos y no se alcanza de golpe, aunque es emergente. Citado por Fariñas, (2008).

22 Para Fariñas (2008), en este caso el proceso se convierte en cualidad e igualmente una cualidad no se acaba porque el ser humano está en movimiento permanente, como lo está la realidad de la que forma parte. 
Es este un nuevo punto de coincidencia entre las perspectivas vigotskyana y la freiriana, ya que para Freire la conscientización no es solamente conocer la realidad, sino que la toma de conciencia significa pasar de la inmersión en la realidad, a un distanciamiento de la misma. Ese pasaje se da a través del análisis crítico; es decir, al conocer las razones de ser de la situación concreta, el desafío es trasformar esa realidad que está provocando ese malestar individual y o colectivo. La situación conflictiva, entonces, asumida críticamente demanda el cambio de lo que la provoca $-y$ no de los sujetos que la viven, como se hace usualmente desde una perspectiva administrativa- empresarial-. Desde este punto de vista, la educación apunta a la transformación de la realidad para hacerla más humana, permitiendo así que los seres humanos se hagan sujetos de la historia, dejando de ser objetos de la misma.

A continuación trascribimos una unidad de diálogo que recupera la vivencia grupal en torno a un conflicto compartido por una de las personas participantes, donde se pone de manifiesto cómo la situación se solucionó institucionalmente y cómo los sujetos del foro virtual muestran sus discrepancias con la misma, precisamente como un ejemplo de toma de conciencia ${ }^{23}$ :

(A): “(...) al finalizar el año escolar el Consejo de Sección, integrado por todos los docentes que imparten clase en un año y en una sesión especifica, discuten los casos de los estudiantes, cuyas actuaciones han generado situaciones graves de indisciplina, (...) el Consejo sugirió cambiar a los estudiantes para otra sección y disolver los grupos propiciadores de las situaciones perturbadoras. Dos estudiantes a quienes se les aplicó la medida, han manifestado su inconformidad por la decisión, alegando que en el nuevo curso los compañeros no los integran y solicitan se revoque la decisión (...)"(May.) (F): 10 de octubre de 2008. (L): Venezuela. (O): Maestra de enseñanza básica.

(A): “(...) yo no soy partidario de que se separen a los indisciplinados de sus cursos; (...) yo lo hice en una ocasión (...) y no lograron adaptarse, se sentían constantemente mal en el curso; además los miraban mal, eran los indisciplinados y eso los afectamos mucho a ellos, como personas." (Ne.) (F): 11 DE OCTUBRE DE 2008. (L): Ecuador. (O): Coordinador Movimiento Popular Fe y Alegría.

(A): "Me parece muy interesante el caso que nos compartes. Sin embargo en lo personal no comparto la medida aplicada. (...) ya que no resuelve el problema, (...) sólo lo cambia de lugar, (...). Como dice el texto que acabamos de leer: "la violencia estructural tiene que ver

23 Tal toma de conciencia se ve particularmente en la intervención de (Gr.), cuando manifiesta su criticidad a través de la lectura realizada sobre la "violencia estructural..." a la cual atribuye que las personas estén insatisfechas porque no pueden cubrir sus necesidades. En otras palabras, (Gr.) se hace consciente de que existen situaciones estructurales que, si no cambian, no hay posibilidades de desarrollo real, como sujetos de la historia. 
con los modelos organizativos y estructuras injustas que mantienen a las personas en la insatisfacción de sus necesidades". (...) sugeriría que se tratará de implementar algunos de cambios estructurales, sugeridos en la lectura revisada e intentar nuevamente el análisis y la negociación del conflicto, donde todos expongan, participen y se hagan valer los derechos propios y ajenos. Así, todos ganan." (Gr.) (F): 11 de octubre de 2008. (L): México, Jalisco, Guadalajara. (O): Directora de primaria.

(A): "Gracias por sus comentarios. Estoy de acuerdo con ustedes en que la solución no debió ser cambiarlos de grupo; sin embargo la decisión no dependía de mí y el Consejo impuso su parecer. Voy a compartir con los docentes las opiniones que me envían y vamos a ver qué pasa." (Ma.E) (F): 13 de octubre de 2008.

En este diálogo vemos nuevamente cómo emergen ideas del psicólogo ruso y del pedagogo brasileño. Desde los aportes epistémicos de Vigotsky identificamos un intercambio de ideas entre gente educada, maestros progresistas que siguen su proceso de autoformación; lo que queda demostrado en la mención que uno de ellos hace sobre lecturas recientemente realizadas que sugieren cómo trabajar la situación conflictiva para que todos los involucrados en la misma se desarrollen como sujetos, siendo actores en el proceso de aprendizaje.

Ello nos remite a las etapas del proyecto educativo desde la perspectiva históricocultural, haciendo referencia nuevamente a los aportes interpretativos de G. Fariñas (2007, p.54), quien -citando a V.V. Davidov y a V. I. Slovodchikov (1999, p. 124)-, dice que: "todo proyecto de desarrollo humano desde la óptica de la educación, debía seguir determinadas etapas en su diseño y realización (convergentes) en las disciplinas relativas al desarrollo".

De las seis etapas mencionadas por Fariñas, el diálogo en torno al conflicto en cuestión, reconocemos dos de las mismas: 1) "la definición pedagógica de la finalidad del proceso educativo, ligada a la formación de la personalidad". (Lo cual se manifiesta en las participaciones que enfatizan a: “... no resuelve el problema...sólo lo cambia de lugar... b: "no soy partidario de que se separen a los indisciplinados... no lograron adaptarse, se sentían constantemente mal en el curso..."). 2) "el análisis lógico y psicológico de la actividad conjunta de alumnos y maestros, cuya realización lleva a la formación de las cualidades de la personalidad". (Principio manifestado en la idea: "intentar nuevamente el análisis y la negociación del conflicto, donde todos expongan, participen y se hagan valer los derechos propios y ajenos. Así, todos ganan.).

En cuanto a la solución dada por el Consejo institucional nos remite a la problemática situación del "enraizamiento cultural" de nuestros sistemas educativos que, como explica Fariñas (2007, p. 191) citando a F. Savater (1997), "Tanto los programas tradicionalistas de 
preparación de los maestros como la rutina diaria tienden a perpetuar determinados saberes cerrados". En este caso es darle la solución a un conflicto eliminando al que aparentemente lo provoca (prácticas de educación bancaria, diría Freire, que buscan la solución a través del "chivo expiatorio", en lugar de asumir el conflicto socialmente y darle una solución que haga crecer al grupo y cada uno de sus integrantes).

Y ya que mencionamos a Freire ¿qué diría en este "mano a mano" que hemos planteado con Vigotsky? Interpretando que él asume el proceso educativo como una acción cultural relacionada a un proceso de conciencia crítica, liberadora, antiautoritaria, no discriminadora y -por consiguiente- incluyente, empática y tolerante. Entendemos que la voz del pedagogo-político brasileño se hace oír en lo que menciona uno de los participantes en el diálogo virtual, (remitiéndose primero, a la lectura recientemente realizada -misma que se contempla en el diseño del Módulo que cursa-) : “... la violencia estructural tiene que ver con los modelos organizativos y estructuras injustas que mantienen a las personas en la insatisfacción de sus necesidades (...). La lectura lo motiva para sugerir: “... que se tratará de implementar algunos cambios estructurales, sugeridos en la lectura revisada e intentar nuevamente el análisis y la negociación del conflicto, donde todos expongan, participen y se hagan valer los derechos propios y ajenos. Así, todos ganan."

\subsection{Otra experiencia conflictiva compartida}

(A): "Una de las situaciones que con mayor frecuencia se presentan en la escuela es el tipo de conductas violentas de los alumnos, los cuales llegan a agredir verbalmente a sus compañeros; a veces es la burla al otro, la amenaza, o los accidentes que ocurren en el patio de la escuela en horas de recreo (...). La forma en que maneja estas situaciones (...) en la dirección es: Les ofrezco asiento para que se pongan cómodos (...). A cada una de las partes involucradas, le doy su turno para exponer sobre lo ocurrido, solicitándoles que no interrumpan a su compañero hasta que termine de hablar; ya que cada uno expone sobre lo ocurrido. Luego les pregunto: ¿Esa es la manera de arreglar las cosas? ¿Les parece bien? (...) La plática termina cuando ellos dictaminan una sanción para sí mismos (...) Pero bueno, hay que seguir haciendo lo nuestro y tal vez ahora con los elementos recuperados en este curso; se me ocurre que se pueda diseñar un taller para padres, maestros y niños, sobre: ¿Cómo resolver conflictos? (G.) (F): 9 de octubre de 2008. (L): México, Jalisco, Guadalajara. (O): Directora de escuela primaria.

(A): "¡La situación que planteas me resulta tan familiar...! Quizás esa sea una constante también, en mi escuela. Considero que las estrategias que planteas, ciertamente, mejoran la situación, pero es posible que no sean suficientes (...). Por experiencia sé que estas situaciones no son fáciles; sin embargo al igual que tú, creo que con los aportes de todos 
podemos encontrar mejores camino..."(Ma.) (F): 13 de octubre de 2008. (L): México, Guanajuato, Acámbaro. (O): Psicóloga Educativa.

(A): “(...) las soluciones que has adoptado son muy buenas, porque desde el momento en que los llamas a dialogar, has creado ese ambiente de confianza que pocas veces ven los estudiantes. Además, les has dado la oportunidad para que se expresen y ambas partes manifiesten cómo sucedió y luego, ellos mismos pongan una solución a lo ocurrido. En este sentido me parece que llevaste muy bien la situación, y te felicito. (..)"(N.) (F): 11 de octubre de 2008. (L): Ecuador. O: Coordinador Movimiento Educación Popular de Fe y Alegría.

(A): “(...) Me da gusto que tengas una postura abierta a mejorar las técnicas que hasta el día de hoy has aplicado. Me gusta el ejemplo que das, porque es cotidiano y describes claramente la situación que se presenta con sus respectivas soluciones así como los resultados de esas acciones." (M.) (F): 13 de octubre de 2008.

En este diálogo virtual se reconocen tres unidades: a) La vivencia del proceso llevado a cabo por la participante, en el ejercicio de su labor cotidiana como directora de un plantel educativo. b) El intercambio de ideas entre los participantes del foro virtual. c) La toma de conciencia a través de una actitud crítica ante la realidad.

Las acciones de quien plantea el conflicto y las estrategias de solución que comparte evidencian el pensamiento de Vigotsky en cuanto a que "los signos y las palabras sirven, primero y ante todo, como instrumentos para el contacto social con el otro" (1978a, p. 29) ${ }^{24}$. Vemos en este proceder la cooperación social llevada a cabo a través de los signos verbales utilizados como instrumentos psicológicos que conlleva, como resultado, el contacto con uno mismo. Ese análisis de la situación conflictiva, propuesto por la directora, es un análisis de los signos verbales que permite elaborar una actuación consciente, en este caso la determinación de la sanción por las mismas personas que causaron la situación de indisciplina.

En cuanto al escepticismo de una de las participantes sobre si es adecuado o no el proceder de quien comparte la experiencia conflictiva encuentra una explicación freiriana, ya que no es la sanción lo que deben construir los participantes de dicha experiencia, sino la manera de elaborar una actitud diferente en ellos mismos para no manifestar acciones violentas. Para ello es necesario saber qué ocasiona tales acciones y no sólo quedarse en si es o no correcto lo que ellos hicieron para autodictaminarse un castigo. Si observamos las

24 Citado por Vera John-Steiner y Carolyn P. Panofsky. (2008). "Procesos sociogenéticos de la comunicación verbal”. En Schneuwly, B. y Bronckart, J.P. (Coord.), Vigotsky hoy, p. 164. 
preguntas planteadas por la persona adulta, vemos que sólo promueven respuestas mecánicas; no detonadoras de una explicación profunda de lo que causa esa violencia.

Es importante el paso dado por la persona adulta, sin embargo, el diálogo que promueve no es horizontal, ya que ella pregunta y espera que le contesten sí o no, según la pregunta (“¿Esa es la manera de arreglar las cosas? ¿Les parece bien? La plática termina cuando ellos dictaminan una sanción para sí mismos"). No obstante, en el planteamiento de la experiencia conflictiva, la persona que lo hace se identifica en dos actitudes diferentes: una con los educandos, otra con sus iguales en el foro virtual

La primera actitud, cuando plantea la experiencia, imaginamos que tanto Vigotsky como Freire moverían la cabeza negativamente. El primero, porque no hay un diálogo que promueva el desarrollo de los sujetos, tampoco se les permite ser actores en la construcción de una nueva situación. El segundo, reconocería el esfuerzo de la directora pero pensaría: "Falta humildad" ("Nadie lo sabe todo, nadie lo ignora todo", Freire, p. 60); "es arrogante" (“... una de las expresiones de la humildad es la seguridad insegura, la certeza incierta y no la certeza demasiado segura de sí misma...", Freire, p. 61); "es autoritaria” (“Es en su verdad donde radica la salvación de los demás (...)", Freire, p. 61).

La segunda actitud, cuando reconoce que, a la luz de lo aprendido en el módulo debería pensar otras soluciones, la percepción que tenemos de ella es diferente, diríamos que contraria a la manifestada en el ejercicio de su profesión. Vigotsky explicaría que tal cambio de actitud se da debido a que el pensamiento y la conciencia del sujeto no se derivan de sus funciones internas, sino que están determinadas de forma compleja por las actividades externas que practica con sus congéneres y la comunicación establecida durante éstas, en un ambiente social dado; por lo tanto, el cambio de actitud se da motivado por el tipo de semejante con quien está interactuado, la manifestación de la actitud con sus alumnos es diferentes a la actitud con adultos que, estando en un mismo nivel que ella, considera que pueden aportar más a su desarrollo. Gran error ya que, “... El aprendizaje del educador al educar (...) (es) busca(r) involucrarse en la curiosidad del alumno, y los diferentes caminos y senderos que ella lo hace recorrer..." (Freire, p. 29)

\section{Concluir para... volver a empezar}

Para terminar diremos que la experiencia del diseño del Módulo I: "Pilares y desafíos de la convivencia escolar", así como la corresponsabilidad tripartita de la tutoría en línea, nos conmina a comenzar nuevamente. 
Re-pensar lo hecho, re-laborar lo diseñado a la luz de los procesos que todos y todas las y los participantes dejan, como experiencias de aprendizaje en los registros de la plataforma, donde se recuperen aquellos elementos que ocasionaron la conciencia como un proceso originado en actitudes críticas de las situaciones conflictivas evidenciadas, con el objetivo de provocar propuestas sustanciales para el cambio de las realidades que provocan la existencia de tales situaciones conflictivas.

Sabemos que ello implica un desafío; sin embargo, el mismo se entiende como insoslayable, si queremos seguir siendo coherentes con las premisas vigotskyanas y freirianas. Desafío que implica: (1) La asunción dialéctica del hecho educativo, como proceso complejo por sus múltiples facetas y las variadas dinámicas que ellas proponen, demandante de (2) teorías que expliquen la práctica y, paralelamente, asumir a ésta como (3) praxis reflexiva. En resumidas cuentas, (4) la asunción de una humildad que lleva implícito el propio desarrollo como adulto y académico en constante aprendizaje.

A manera de cierre de este artículo se transcriben algunas opiniones de los participantes sobre la experiencia generada en el Módulo I:

(A): "Los aprendizajes y el conocimiento son como la buena comida, se ven, se huelen, se degustan, se disfrutan, pero el verdadero efecto se ve cuando se hace la digestión. En otras palabras, así en este primer módulo: Compartimos reflexionamos, dialogamos leímos y practicamos. Pero el verdadero efecto lo veremos cuando ganemos en cada una de nuestras comunidades, las voluntades de las personas para generar verdaderos procesos de convivencia. En mi Institución Educativa he implementado dos talleres de 4 horas cada uno, con una metodología participativa, con los docentes de básica primaria y secundaría, con base en la lectura de dos documentos, los cuales me han generado discusión en torno a la convivencia. El proceso del Módulo I ha sido muy bueno, por los documentos y la manera secuencial como están escogidos los documentos, además que es excelente que tantas personas investiguen y piensen desde la convivencia escolar. Para terminar los aportes en términos de opinión frente a los productos de los compañeros ha resultado una experiencia interesante, por las diferentes experiencias de cada país o región en las similitudes y las diferencias, pero me asombran más las similitudes." (An.) (F): 25 de octubre de 2008. (L): Colombia. (O): Maestra

(A): "Aunque no soy de tu equipo, pero me sirven las observaciones que haces. Además, porque las observaciones que hacemos a los demás son las que nos hacemos a nosotros mismos. Me digo a mí misma y lo tomaré en cuenta cuando ese servicio me corresponda. / La dinámica de participación me parece interesante, así todos podemos hacer un trabajo de compartir y de reflexión que nos aporte. La misma dinámica de la página y metodología empleada nos lleva a crear lazos y espacios de convivencia virtual." (Te.) (F): 29 de septiembre de 2008. (L): Ecuador. (O): Pastoral en "Fe y Alegría" Movimiento de educación popular. 
(An.I.) (F): 22 de octubre de 2008. (L): Chile. (O): Orientadora en el Liceo Diego de Almeida, que pertenece a la Fundación Educacional el Salvador. (A): "Les comento que mi experiencia de aprendizaje ha sido muy positiva, en el sentido de interactuar y compartir ideas y opiniones con ustedes. Realmente aquí se da la construcción del aprendizaje y, con ello, la posibilidad de extender esta experiencia a otros docentes de mi comunidad educativa; porque la esperanza y confianza en que podemos construir una mejor convivencia es posible, con el apoyo de todos."

(A): "Los valores dan sentido a la propia existencia". (Pérez Juste, 1998, p.234) "Compañeros: gracias por escribirnos y compartir sus experiencias. El curso que plantea el Módulo I, reitero que lo siento muy ambicioso, ya que rebasó mis expectativas, -en tiempo, sobre todo-; pero su contenido dio lugar a que, compañeros y compañeras (así como el propio curso), ofrecieran elementos, para entender el por qué de muchas situaciones que implica la propia convivencia escolar. Así mismo proporcionó alternativas (modelos) para resolver las situaciones, presentes en los centros escolares o en determinados grupos. Sí, los valores dan sentido a la existencia, por lo tanto, es importante darle un sentido al curso de la convivencia escolar y llevarlo a nuestros ámbitos laborales. Y como: "enseñar no es transferir los conocimientos" (Paulo Freire), es necesario que realicemos un nuevo análisis de todo lo que hemos dialogado, leído y compartido, para ver qué es lo factible de poner en práctica en nuestra escuela, en nuestras propias clases, en nuestra propia persona. Y para ello considero que se requiere "hacernos cargo de las propias conductas", dentro y fuera del aula, donde se pueden ir creando espacio de convivencia escolar. (...)"(Ti.) (F): 22 de octubre de 2008. (L): México, Guadalajara. (O): Académica.

\section{Referencias}

Daniels, Harry. (2003). Vygotsky y la pedagogía. Barcelona: Paidós.

Fariñas León, Gloria. (2006). L. S. Vigotsky en la educación superior contemporánea: perspectivas de aplicación. Cursos Universidad. Curso 2. La Habana: La Universalización de la Universidad por un Mundo Mejor.

Fariñas León, Gloria. (2007). Psicología, educación y sociedad. Un estudio sobre el desarrollo humano. La Habana: Editorial Félix Varela

Fariñas León, Gloria. (2008). Foro virtual. Plataforma virtual de la Red Latinoamericana de Convivencia Escolar.

Freire, Paulo. (2002). Cartas a quienes pretenden enseñar. México: Siglo XXI. 8ª edición.

Gadotti, Moacir y Torres, Carlos Alberto (Coord.). (2001). Paulo Freire. Una bibliografía. México: Siglo XXI.

Riviere, Angel. (1988). La psicología de Vygotski. España: Visor Distribuciones. 
Rojo, Flavio. (2008). Algunos temas a desarrollar para la convivencia escolar. Antología, documento para el trabajo interno de la Red Latinoamericana de Convienvencia Escolar.

Gadotti, Moacir y Torres, Carlos Alberto. (Coord.). (2001). Paulo Freire. Una bibliografía. México: Siglo XXI.

Schneuwly, B. y Bronckart, J.P. (Coord.) (2008). Vigotsky hoy. España: Ministerio de Educación-Editorial Popular.

Vigotsky, Lev S. (2008). Las raíces genéticas del lenguaje (Tomado de Pensamiento y lenguaje). En Schneuwly, B. y Bronckart, J.P. (Coord.) Vigotsky hoy, (pp. 41 - 54). España: Ministerio de Educación-Editorial Popular.

Wertsch, James V. (2008). La mediación semiótica de la vida mental: L.S. Vigotsky y M.M. Bajtín. En Schneuwly, B. y Bronckart, J.P. (Coord.), Vigotsky hoy, (pp. 111 - 134). España: Ministerio de Educación-Editorial Popular. 